\title{
Evaluation of the clinical efficiency of rotary and manual files for root canal instrumentation in primary teeth pulpectomies: A comparative randomized clinical trial
}

(D) KL Girish Babu ${ }^{1} \bowtie$, (D) Guraj Hebbar Kavyashree ${ }^{2}$

\section{Highlights}

The application of rotary endodontics is still new in pediatric dentistry. Rotary files manufactured primarily for permanent teeth are routinely used in primary teeth.

\section{Professor \& Head, \\ Department of Dentistry, \\ Hassan Institute of Medical Sciences, \\ Hassan-573201, India \\ 2 Junior Resident, \\ Department of Dentistry, \\ Hassan Institute of Medical Sciences, \\ Hassan-573201, India}

HERO Shaper rotary file system is manufactured for permanent teeth but its design makes it convenient to use in primary teeth. Recently, Kedo-S pediatric rotary file system was introduced for use in primary teeth.
The rotary file systems showed superior obturation quality, decreased instrumentation time, and decreased obturation time compared to manual files.

\section{Abstract}

Aim: To evaluate and compare the instrumentation time, obturation time, quality of obturation, and clinical and radiological success of pulpectomized teeth following root canal preparation of primary molars with rotary and manual file system. Methods: A total of 150 primary molars requiring pulpectomy were selected from children aged four to seven years. These teeth were divided into three groups of 50 teeth each. In Groups 1, 2, and 3, cleaning and shaping were carried out with Kedo-S pediatric rotary files, HERO Shaper rotary files, and manual NiTi K-files, respectively. Obturation was carried out with zinc oxide eugenol cement and an engine-driven Lentulo spiral. The instrumentation and obturation times were recorded. A radiographic assessment of the quality of the root filling was carried out immediately after obturation. Finally, the pulpectomized teeth were clinically and radiographically evaluated over a two-year period. Results: The mean instrumentation times for Groups 1, 2, and 3 were $14.56 \pm 2.89 \mathrm{~min}, 17.93 \pm$ $3.51 \mathrm{~min}$, and $29.00 \pm 2.08 \mathrm{~min}$, respectively. The mean obturation times for Groups 1, 2, and 3 were $8.11 \pm 1.7 \mathrm{~min}, 7.93 \pm 1.3 \mathrm{~min}$, and $9.64 \pm 17.61 \mathrm{~min}$, respectively. The mean difference in the quality of obturation was not statistically significant in primary molars instrumented with Kedo-S pediatric and HERO Shaper rotary file systems $(p=0.16)$. However, this mean difference was significant when compared between primary molar instrumented with rotary file systems and manual NiTi files $(p=<0.001)$. At two years, the clinical success rate was $100 \%$ and the radiological success rates were 95.3\%, 97.9\%, and 89.5\% in Groups 1, 2, and 3, respectively. Conclusions: The rotary file systems took significantly less instrumentation and obturation time than the manual NiTi files. There were no significant differences in obturation quality or success rates after two years.

Keywords: Endodontic Obturation; Instrumentation; Pulpectomy; Root Canal Preparation

Received: 20 February 2021

Accepted: 19 April 2021

Online First: 22 April 2021 


\section{INTRODUCTION}

The use of rotary instruments in pediatric endodontics was introduced by Barr et al., ${ }^{1,2}$ who found that the use of NiTi rotary files for root canal preparation in primary teeth is costeffective, fast, and produces consistently uniform, predictable results. Since then, many rotary endodontic systems have been recommended for root canal cleaning and shaping in primary teeth. ${ }^{3-}$ 7 However, NiTi file systems are primarily manufactured for use in permanent teeth. The use of these files in primary teeth may lead to lateral perforations, as primary teeth have shorter, thinner curved roots compared to permanent teeth and a ribbon-shaped morphology. ${ }^{8,9}$

One rotary file system that is manufactured for permanent teeth but convenient to use in primary teeth is the HERO Shaper rotary file system. ${ }^{10}$ The HERO Shaper rotary file system incorporates a conical design with high flexibility and a constant taper. The modified file design prevents a screw-like action and thus prevents the instrument from binding to the root canal. ${ }^{10}$ Additionally, HERO Shaper rotary files have short metallic shafts with non-cutting tips, making them more appropriate for use in primary teeth. ${ }^{11}$ The Endoflare is a separate \#25 file, with a short blade length of $15 \mathrm{~mm}$ and a working length of 10 $\mathrm{mm}$, that is suitable for the shorter root canal lengths of primary teeth. The 0.12 taper and positive cutting angle of the Endoflare allow for better cutting and excellent debridement, and its non-cutting tip makes it safer for use in primary teeth. The Endoflare is only used to flare the coronal third at the beginning of the shaping process. ${ }^{11,12}$ This is particularly suitable for primary molars where there is an abrupt cervical constriction and dentinal shelf covering the canal orifice. ${ }^{11,12}$

The Kedo-S pediatric file system is an exclusive, recently introduced pediatric rotary file system. ${ }^{13}$ This system consists of three NiTi files (D1, E1, and U1) with an altered working length of $12 \mathrm{~mm}$ to expedite its use in primary teeth. The D1 and E1 files are designed for the instrumentation of molars, and the $\mathrm{U} 1$ files are designed for anterior teeth. Another added feature of this file system is the presence of a variably variable taper. ${ }^{9,13}$

Independent studies ${ }^{10,11-18}$ have evaluated the immediate outcomes of the HERO Shaper rotary file system and Kedo-S pediatric rotary file systems and shown that they produce superior results. These trials are either in-vitro or crosssectional in nature. No published scientific studies have evaluated the clinical efficiency of these two rotary file systems for the root canal instrumentation of primary teeth over a two-year period. Therefore, the objectives of the present study were to evaluate and compare (1) the instrumentation time, obturation time, and quality of obturation and (2) the clinical and radiological success of pulpectomized teeth following the root canal preparation of primary molars with Kedo-S pediatric rotary file system, HERO Shapers rotary file system, and manual NiTi K-files.

\section{METHODS}

Prior to the beginning of this study, ethical clearance was obtained from our institutional review board (IEC/HIMS/RR76). The study protocol followed the guidelines provided by the World Medical Association's Declaration of Helsinki on Ethical Principles for Medical Research. The CONSORT guidelines for planning and reporting clinical trials in pediatric endodontics were followed throughout the different stages of the study (Figure 1). The study sample included normal, healthy, and cooperative children aged four to seven years visiting our department for pulpectomy of their primary molars.

The sample size was calculated based on previous studies. ${ }^{12,13,15,18}$ The prevalence of optimal fills in rotary file systems is $76.7 \%$. Thus, 


$$
\begin{gathered}
\mathrm{Z}=1.96(\text { constant for } 95 \% \mathrm{CI}) \\
\mathrm{P}=76.7 \%=0.767 \\
\mathrm{Q}=1-\mathrm{P}=1-0.0767=0.233 \\
\mathrm{~d}=\text { Precision }(5-20 \% \text { of } \mathrm{P})=16 \% \text { of } 76.7 \% \\
=12.2 \%=0.122 \\
\mathrm{n}=\underline{\mathrm{Z}^{2} \mathrm{PQ}} \quad \mathrm{d}^{2}=\frac{(1.96)^{2} \times 0.767 \times 0.233}{(0.122)^{2}} \\
=45
\end{gathered}
$$

Thus, the estimated sample size was 45 , which was rounded off to 50 .

The nature and objectives of the study were explained to the parents of the participating children, who then provided their informed written consent. The participants' confidentiality was ensured with the use of identification numbers, and their records were maintained by the principal investigator alone. Intraoral examinations were performed and standardized intraoral periapical radiographs were taken for the teeth to determine whether pulpectomy was indicated. The sample inclusion criteria covered teeth that exhibited one or more of the following features: 1) carious pulp exposure diagnosed with irreversible pulpits, 2) vital or non-vital primary molars without a sinus tract, 3) an absence of internal or external pathological root resorption, 4) radiographic signs of pulpal or inter-radicular involvement, or 5) the presence of two-thirds of root length.1,19,20 The exclusion criteria covered teeth with any of the following characteristics: 1) an abscess or sinus tract due to dental caries, 2) non-restorability, 3) pulpal floor perforation, 4) root resorption of more than one-third, or 5) an excessive pathologic loss of bone support with a loss of normal periodontal attachment. Additionally, children who had special care needs, had limited or lacking cooperative abilities, or required sedation/general anesthesia for behavior management were also not included. 1,19,20

The study sample comprised 150 teeth from the selected children. Computer-generated randomization was used to sort these primary molars into three groups (Group 1, Group 2, and Group 3), each consisting of 50 teeth, according to the type of instrumentation to be used for root canal preparation. The root canals in Group 1 were instrumented with the Kedo-S pediatric rotary file system (Reeganz Dental Care Pvt. Ltd., India), those in Group 2 were instrumented with the HERO Shaper rotary file system (Micromega, Geneva, Switzerland), and those in Group 3 were instrumented with manual NiTi K-files (Dentsply, Switzerland).

The pulpectomy procedure was carried out under stringent aseptic conditions by a single pediatric dentist with experience using both rotary and manual instrumentation techniques. Routine nonpharmacological behavior management techniques were used throughout the procedure. Following the administration of local anesthesia (2\% lignocaine, Lignox, Bangalore, India), dental caries and overhanging enamel were removed with a \#330 high-speed bur under a water spray. The coronal pulp was accessed using a \#8 round bur, and the entire roof of the pulp chamber was removed. Necrotic tissue was removed from the pulp chamber with a sterile sharp spoon excavator (2 mm, EXC31W, \#41 Round, 31W Endo Excavators, Hu-Friedy Mfg. Co., LLC). After straight-line access was obtained, pulp tissue was extirpated from the root canal using $\mathrm{H}$-files (Mani, Inc., Tochigi, Japan). A \#10 K-file (Mani, Inc., Tochigi, Japan) was then used to access the patency of the root canal. The working length was determined by superimposing an endodontic instrument over the preoperative radiograph and keeping it 1-2 $\mathrm{mm}$ short of the radiographic apex. ${ }^{12,13}$

The root canals in Group 1 were instrumented with the Kedo-S pediatric rotary file system (Reeganz Dental Care Pvt. Ltd., India) according to the manufacturer's instructions. The D1 rotary files were used for preparation of the mesiobuccal and mesiolingual root canals of mandibular teeth and, mesiobuccal and distobuccal root canals of 
maxillary teeth. E1 rotary file was used for preparation of the distal root canal of mandibular teeth and palatal canal of maxillary teeth with a lateral brushing motion. ${ }^{13}$ The root canals in Group 2 were instrumented with the HERO Shaper rotary file system (Micromega, Geneva, Switzerland) and a coronal-enlarging file (Endoflare-Micromega, Geneva, Switzerland) provided with the file system. The root canals were first instrumented up to the coronal onethird using an Endoflare file at 4-point torque. Then, the root canals were enlarged to working length according to the sequence recommended by the manufacturer. ${ }^{12}$ The rotary file systems used for Groups 1 and 2 were operated with an endodontic motor (X-Smart, Dentsply Maillefer, OK, USA) at $300 \mathrm{rpm}$ and $2.2-\mathrm{Ncm}$ torque. ${ }^{13}$ The root canals were not entered more than twice with each rotary file; this was ensured to prevent unexpected lateral perforation, especially in severely curved root canals. ${ }^{21}$ The root canals in Group 3 were instrumented with manual NiTi Kfiles (Dentsply, Maillefer, Ballaigues,Switzerland). A minimum-size file provided resistance for intracanal placement until the working length was determined as an initial file. The root canals were enlarged up to three times the size of the initial file. Then, the root canals were cleaned and shaped using a pullback motion. ${ }^{13}$

In all three groups, each file was used on up to five teeth to maintain uniformity during root canal preparation. ${ }^{13,21}$ If a point of resistance was encountered, no attempt was made to go beyond it; this was ensured to lower the risk of instrument fracture. ${ }^{21}$ All of the root canals were prepared with intermittent irrigation using a standard 5-ml volume of normal saline. During root canal preparation, 17\% EDTA gel (RC Help, Prime Dental Products, Pvt. Ltd.) was used as a lubricating paste. ${ }^{13}$ Following complete root canal preparation, final irrigation was carried out with saline, and the root canals were dried with absorbent paper points. The root canals of the primary molars in all three groups were obturated with zinc oxide eugenol cement (Zinc Oxide BP, Eugenol BP, Associated Dental Products Ltd.) using a Lentulo spiral mounted on a slow-speed handpiece. The selected Lentulo spiral was one size smaller than the last-used file size and was cut to half its length with a pair of sharp scissors to facilitate handling. A homogenous mixture of zinc oxide eugenol was mixed in a powder: liquid ratio of 1:1. The prepared paste was carried into the root canal using a slow-speed handpiece rotating in a clockwise direction, which was then gently withdrawn from the root canal while still rotating. A rubber stopper was used to keep the Lentulo spiral $1 \mathrm{~mm}$ short of the working length. This process was repeated five to seven times for each root canal until the canal orifice was filled with the paste. 22,23 The pulp chamber was cleaned with a moist cotton pellet and then restored with type II glass ionomer cement (GC, India). ${ }^{13,20}$ Some of the younger children could not bear the long appointments required to maintain the standardized procedure. Hence, for these children, the final restoration with stainless steel crowns (3M ESPE, St. Paul, MN, USA) was carried out in a second appointment within one week of obturation. All the participants were instructed to report any symptoms following the procedure, such as pain or swelling.

The instrumentation and obturation times were calculated by a trained dental assistant using a stopwatch. Instrumentation time is the amount of time required to negotiate and shape all the root canals of a tooth to the desired size after root canal access opening and working length determination. Obturation time is the amount of time required to obturate all the root canals of a tooth after instrumentation. ${ }^{13,20}$ Immediate postoperative radiographs were taken with a dental X-ray unit operating at $60 \mathrm{kvp}, 6 \mathrm{~mA}, 0.3$ seconds, and $15 \mathrm{~mm}$. These radiographs were evaluated for quality of obturation by two pediatric dentists who were blinded to the type of instrumentation used. A kappa test was performed for these examiners, producing scores 
of 0.88 and 0.95 for the inter-examiner and the intra-examiner, respectively. The examiners graded each radiograph as underfilled, optimally filled, or overfilled (modification of Coll and Sadrian). ${ }^{19,24}$
Whenever there was disagreement between examiners, lower ranking was chosen.

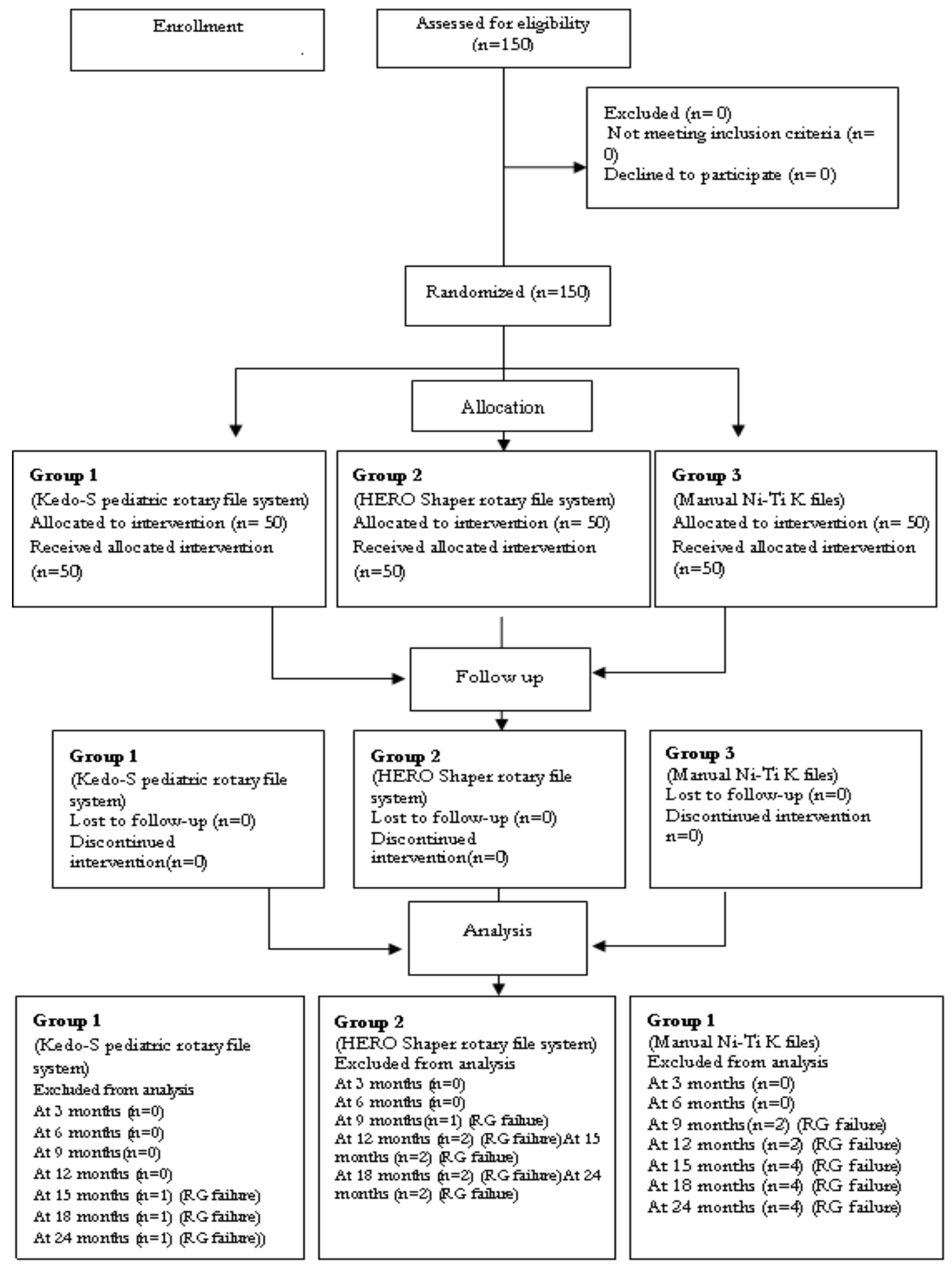

Figure 1. CONSORT flow chart 
The pulpectomized teeth were clinically and radiographically evaluated at regular three-month intervals over a period of two years postoperatively. This frequent follow-up schedule was used to reduce participant dropout. The two aforementioned independent examiners evaluated the success of the pulpectomies. Once again, a kappa test was performed for these examiners, producing scores of 0.87 and 0.90 for the interexaminer and the intra-examiner, respectively. Whenever there was a disagreement between their interpretations, the evaluators jointly reviewed and discussed the radiographs in question until they reached an agreement. If the disagreement remained, then the outcome was recorded as a failure. The pulpectomized teeth were judged clinically and radiographically successful based on the modified criteria provided by Coll and Sadrian. ${ }^{24}$ Clinical success and radiographic success were determined independently, as not all radiographic failures are associated with clinical symptoms and vice versa. ${ }^{20,25}$ The participants, outcome assessors, and data analysts were blinded to the type of instrumentation used; however, the operator could not be blinded due to the recognizable characteristics of the rotary and manual files.

\section{Statistical analysis}

The data were entered into a Microsoft Excel spreadsheet and statistically analyzed with SPSS 19.0 (IBM SPSS Statistics for Windows, Version 19.0, released 2010, IBM Corp., Armonk, NY). Kruskal-Wallis and Chi-square tests were used for comparisons, and a Mann-Whitney post hoc analysis was used for intergroup comparisons.

\section{RESULTS}

The mean age of the participating children was $5.67 \pm 0.178$ years. A total of 66 maxillary teeth and 84 mandibular teeth were treated by pulpectomy. To maintain an equal distribution of teeth, the primary molars were distributed in such a way that all three groups [Group 1 (Kedo-S pediatric rotary file system), Group 2 (HERO Shaper rotary file system), and Group 3 (manual NiTi K-files)] had the same number and types of teeth. There was no drop-out upon follow-up at any point in the evaluation period.

The mean instrumentation times for Groups 1,2 , and 3 were $14.56 \pm 2.89 \mathrm{~min}, 17.93 \pm 3.51$ min, and $29.00 \pm 2.08 \mathrm{~min}$, respectively. The mean differences between Groups 1 and 3 and between Groups 2 and 3 were statistically significant (Tables 1 and 2).

Table 1. Comparison of mean instrumentation time (in minutes) between three groups

\begin{tabular}{|c|c|c|c|}
\hline Groups & $n$ & Mean \pm SD & $\begin{array}{l}P \\
\text { value }\end{array}$ \\
\hline $\begin{array}{l}\text { Group } 1 \\
\text { (Kedo-S pediatric rotary } \\
\text { file system) }\end{array}$ & 50 & $14.56 \pm 2.89$ & $<0.001^{*}$ \\
\hline $\begin{array}{l}\text { Group } 2 \\
\text { (HERO Shaper rotary } \\
\text { file system) }\end{array}$ & 50 & $17.93 \pm 3.51$ & \\
\hline $\begin{array}{l}\text { Group } 3 \\
\text { (Manual Ni-Ti K files) }\end{array}$ & 50 & $29.00 \pm 2.08$ & \\
\hline
\end{tabular}

Table 2. Inter-group comparisons of mean differences in instrumentation time (in minutes) between three groups

\begin{tabular}{llll}
\hline Group & Groups & $\begin{array}{l}\text { Mean } \\
\text { Difference }\end{array}$ & $\begin{array}{l}\boldsymbol{P} \\
\text { value }\end{array}$ \\
\hline $\begin{array}{l}\text { Group 1 } \\
\text { (Kedo-S }\end{array}$ & Group 2 & -3.37 & 0.75 \\
pediatric & (HERO Shaper & & \\
rotary file & rotary file & & \\
system) & system) & & $<0.001$ \\
& Group 3 & -14.44 & $* 0.001$ \\
(Manual Ni-Ti & & $*$ \\
(HERO Shaper & K files) & -11.07 & \\
rotary file & Group 3 & & \\
system) & Kanual Ni-Ti & & \\
\hline *Mann- Whitney Post hoc Analysis , statistically significant &
\end{tabular}


The mean obturation times for Group 1,2, and 3 were $8.11 \pm 1.7 \mathrm{~min}, 7.93 \pm 1.3 \mathrm{~min}$, and $9.64 \pm$ $1.61 \mathrm{~min}$, respectively. The difference between Groups 1 and 2 was not statistically significant. However, a significant difference did appear when Groups 1 and 2 were compared with Group 3 (Tables 3 and 4). In Group 1, 9 (18\%) teeth were underfilled, $33(66 \%)$ teeth were optimally filled, and $8(16 \%)$ teeth were overfilled. In Group 2, 3 $(6 \%)$ teeth were underfilled, $35(70 \%)$ teeth were optimally filled, and $12(24 \%)$ teeth were overfilled. In Group 3, 15 (30\%) teeth were underfilled, $25(50 \%)$ teeth were optimally filled, and $10(20 \%)$ teeth were overfilled. Groups 1 and 2 showed significantly better obturation quality compared to Group 3. However, obturation quality did not significantly differ between Groups 1 and 2 (Tables 5 and 6).

Table 3. Comparison of mean obturation time (in minutes) between three groups

\begin{tabular}{lcll}
\hline Groups & n & Mean \pm SD & $\begin{array}{l}\boldsymbol{P} \\
\text { value }\end{array}$ \\
\hline $\begin{array}{l}\text { Group 1 } \\
\text { (Kedo-S pediatric }\end{array}$ & 50 & $8.11 \pm 1.7$ & $<0.001^{*}$ \\
rotary file system) & & & \\
Group 2 & 50 & $7.93 \pm 1.3$ & \\
(HERO Shaper & & & \\
rotary file system) & & & \\
$\begin{array}{l}\text { Group 3 } \\
\text { (Manual Ni-Ti K files) }\end{array}$ & 50 & $9.64 \pm 17.61$ & \\
\hline
\end{tabular}

*Kruskal Wallis test, statistically significant
At the end of two years, the clinical success rate was $100 \%$ and the radiological success rates were $95.3 \%, 97.9 \%$, and $89.5 \%$ in Groups 1, 2, and 3, respectively. An increase in the size of preoperative radiolucency was the only type of radiological failure observed. This failure was observed in Groups 2 and 3 at the nine-month follow-up and continued until the end of the study period. However, it was also observed in Group 1 at the 15-month follow-up, again continuing until the end of the study period. At the end of two years, 3, 9, and 16 teeth were considered radiological failures in Groups 1, 2, and 3 , respectively. The intergroup comparison of clinical and radiographic success over a two-year period did not reveal any statistically significant differences (Table 7).

Table 4. Inter-group comparisons of mean differences in obturation time (in minutes) between three groups

\begin{tabular}{llll}
\hline Groups & Groups & Mean & $P$ \\
& & Difference & value
\end{tabular}

\begin{tabular}{llll}
\hline $\begin{array}{l}\text { Group 1 } \\
\text { (Kedo-S }\end{array}$ & $\begin{array}{l}\text { Group 2 } \\
\text { (HERO Shaper }\end{array}$ & 0.18 & 0.44 \\
pediatric & rotary file & & \\
rotary file & system) & & \\
system) & Group 3 & -1.53 & $<0.001^{*}$ \\
& $\begin{array}{l}\text { (Manual Ni-Ti } \\
\text { K files) }\end{array}$ & & \\
& Group 3 & -1.71 & $<0.001^{*}$ \\
$\begin{array}{l}\text { Group 2 } \\
\text { (HERO Shaper } \\
\text { rotary file }\end{array}$ & (Manual Ni-Ti & & \\
system) & K files) & & \\
\hline
\end{tabular}

*Mann-Whitney Post hoc Analysis, statistically significant

Table 5. Comparison of quality of obturation between three groups

\begin{tabular}{|c|c|c|c|c|}
\hline Groups & $\begin{array}{l}\text { Underfilled } \\
\text { n }(\%)\end{array}$ & $\begin{array}{l}\text { Optimally filled } \\
\mathrm{n}(\%)\end{array}$ & $\begin{array}{l}\text { Overfilled } \\
\text { n }(\%)\end{array}$ & $\begin{array}{l}P \\
\text { value }\end{array}$ \\
\hline $\begin{array}{l}\text { Group } 1 \\
\text { (Kedo-S pediatric rotary file system) }\end{array}$ & $9(18)$ & $33(66)$ & $8(16)$ & $<0.001 *$ \\
\hline $\begin{array}{l}\text { Group } 2 \\
\text { (HERO Shaper rotary file system) }\end{array}$ & $3(6)$ & $35(70)$ & $12(24)$ & \\
\hline $\begin{array}{l}\text { Group } 3 \\
\text { (Manual Ni-Ti K files) }\end{array}$ & $15(30)$ & $25(50)$ & $10(20)$ & \\
\hline
\end{tabular}

*Chi-Square Test, statistically significant 
Table 6. Inter-group comparison of quality of obturation between three groups

\begin{tabular}{llll}
\hline Groups & Group 1 vs Group 2 & Group 1 vs Group 3 & Group 2 vs Group 3 \\
& $\begin{array}{l}\text { (Kedo-S pediatric rotary file system vs } \\
\text { (Kedo-S pediatric rotary file system vs }\end{array}$ & $\begin{array}{l}\text { (HERO Shaper rotary file system vs } \\
\text { Manual Ni-Ti K files) }\end{array}$ \\
\hline$P$ value & 0.16 & Manual Ni-Ti K files) & $<0.001^{*}$ \\
\hline
\end{tabular}

*Chi Square Test, statistically significant

Table 7. Comparison of clinical and radiographical success between three groups

\begin{tabular}{|c|c|c|c|c|c|c|c|c|}
\hline $\begin{array}{l}\text { Evaluation } \\
\text { Period } \\
\text { (month) }\end{array}$ & $\begin{array}{l}\text { Group } 1 \\
\text { Kedo-S } \\
\text { pediatric } \\
\text { rotary file } \\
\text { system }\end{array}$ & $\begin{array}{l}\text { Group } 2 \\
\text { HERO } \\
\text { Shaper rotary } \\
\text { file system }\end{array}$ & $\begin{array}{l}\text { Group } 3 \\
\text { Manual Ni- } \\
\text { Ti K files }\end{array}$ & $\begin{array}{l}P \\
\text { Value }\end{array}$ & $\begin{array}{l}\text { Group 1 } \\
\text { Kedo-S } \\
\text { pediatric } \\
\text { rotary file } \\
\text { system }\end{array}$ & $\begin{array}{l}\text { Group } 2 \\
\text { HERO } \\
\text { Shaper } \\
\text { rotary file } \\
\text { system }\end{array}$ & $\begin{array}{l}\text { Group } 3 \\
\text { Manual Ni- } \\
\text { Ti K files }\end{array}$ & $\begin{array}{l}P \\
\text { Value* }\end{array}$ \\
\hline & n (\%) & n $(\%)$ & n ( $\%)$ & & n (\%) & n (\%) & n (\%) & \\
\hline 3 & $50(100)$ & $50(100)$ & $50(100)$ & - & $50(100)$ & $50(100)$ & $50(100)$ & - \\
\hline 6 & $50(100)$ & $50(100)$ & $50(100)$ & - & $50(100)$ & $50(100)$ & $50(100)$ & - \\
\hline 9 & $50(100)$ & $50(100)$ & $50(100)$ & - & $50(100)$ & 49(98) & 48(96) & 0.36 \\
\hline 12 & $50(100)$ & $50(100)$ & $50(100)$ & - & $50(100)$ & 47(95.9) & $46(95.8)$ & 0.35 \\
\hline 15 & $50(100)$ & $50(100)$ & $50(100)$ & - & 49(98) & $45(95.7)$ & $42(91.3)$ & 0.35 \\
\hline 18 & $50(100)$ & $50(100)$ & $50(100)$ & - & 48(98) & 43(95.6) & $38(90.5)$ & 0.26 \\
\hline 24 & $50(100)$ & $50(100)$ & $50(100)$ & - & $47(97.9)$ & $41(95.3)$ & $34(89.5)$ & 0.22 \\
\hline
\end{tabular}

*Chi-Square Test

\section{DISCUSSION}

In pediatric dentistry, decreased root canal instrumentation time is essential to reduce children's anxiety and increase their cooperation with each step of the clinical procedure. This could also reduce patient and dentist fatigue, thus allowing for faster, safer, and higher-quality treatment. ${ }^{20,26}$ In the present study, significant reductions in root canal instrumentation time were observed for both rotary file systems compared to the manual file system. This finding is consistent with the findings of several prior studies. 14,18,20,26-29 However, contrary to our results, Madan et al. ${ }^{30}$ observed an increase in root canal instrumentation time with the use of a rotary file system in primary teeth. Although the use of rotary file systems for root canal instrumentation in primary teeth took significantly less time than the manual technique, it took relatively more time than in prior studies. ${ }^{13,14,21,26}$ This difference might have been related to the operator's knowledge level, skill level, and experience with rotary endodontics. Also, given that the selected children were of a relatively young age group, the procedure was carried out relatively slowly to ensure their complete cooperation. Between the two rotary file systems used in the present study, the root canal instrumentation time of the Kedo-S pediatric rotary file system was lower than that of the HERO Shaper rotary file system. This can be attributed to the fact that the HERO Shaper rotary file system requires a greater number of files for the sequential enlargement of root canals compared to the Kedo-S pediatric rotary file system.

The amount of time taken for obturation is another important factor in the treatment of children. We observed significantly reduced obturation times in the root canals instrumented with rotary file systems compared to those instrumented with manual files. This might have been due to the fact that the rotary instrumentation technique prepares a relatively wide, conical canal that easily allows for obturating instruments. Additionally, the removal 
of cervical obstructions in the root canals with rotary file systems could have decreased obturation times. However, the use of manual files results in irregularly shaped canals and thus takes more obturation time. ${ }^{20,26,28}$

The quality of root canal obturation is another key factor that determines the success of pulpectomized teeth. In the present study, rotary files produced a greater number of optimally filled root canals than manual files. This finding is similar to the findings of Romero et al.,26 Makarem et al., ${ }^{27}$ and Jeevanadan et al. ${ }^{13}$ The root canals prepared by rotary files are conical in form, and this results in superior obturation quality. 27,31 A rotary file has an elastic memory and a radial land that keeps the file in the center of the root canal via wall support and inactive tips, resulting in conical root canal shapes relative to those produced by manual files. ${ }^{31}$ Additionally, the greater taper of the rotary files could have contributed to the observed improvements in obturation quality. A higher number of underfilled root canals were observed with the use of manual NiTi files. The use of lesser tapered manual NiTi files could have resulted in narrow irregular root canals, which could have prevented the obturating material from flowing adequately. ${ }^{13,15}$ This observation is consistent with the findings of several prior studies. ${ }^{31,13,15-18,27}$ However, in contrast with our results, Morankar et al. ${ }^{20}$ reported that rotary and manual files performed equally in terms of obturation quality.

There was no statistically significant difference in obturation quality between the primary molars instrumented with the Kedo-S pediatric rotary file system and those instrumented with the HERO Shaper rotary file system. This result is consistent with the findings of prior studies that reported superior obturation quality with the use of a rotary file system in primary teeth, irrespective of the type of rotary file system used. ${ }^{17,21,32-34}$ Rotary files debride the uneven walls of primary root canals more effectively and provide dense obturation relative to manual files. ${ }^{1,2}$ The HERO
Shaper rotary file system produced a slightly higher percentage of optimally filled root canals relative to Kedo-S pediatric rotary file system. The use of an Endoflare to pre-enlarge the coronal third of the root canal could have contributed to the observed superior obturation quality. Coronal flaring removes any cervical interference from the root canal entrances, allowing endodontic instruments to freely access the apical portion of the root canal.11,12 Additionally, the increased taper of these rotary files could have shaped the canal into its final conical outline more easily than cylindrical instruments. With a greater taper, the prepared root canals should be wider and more conical, allowing the obturating material to flow up to the apical third more easily. These factors could produce a greater number of optimally filled canals. ${ }^{11,12}$ At the same time, the greatest number of overfilled root canals was noted in the primary teeth instrumented with this file system. This might have been due to the increased length and taper of the HERO Shaper file system, which could have resulted in over-instrumentation, as it is primarily designed for permanent teeth. Another probable explanation is that the correct root canal length might not have been maintained when the rubber stopper was fitted onto the Lentulo spiral. Consistent with the results of prior Indian studies, ${ }^{13,15-18}$ the Kedo-S pediatric rotary file system produced a greater number of optimally filled root canals. Furthermore, the pediatric rotary file system produced the fewest overfilled root canals. This might have occurred because the Kedo-S pediatric file system produces minimal apical enlargement, preventing the overpreparation and extrusion of the obturating material. ${ }^{18}$ Although the obturation materials and techniques varied between the cited studies ${ }^{13,15-18}$ and the present study, the quality of obturation did not vary significantly.

A pulpectomized tooth is considered to be a success when it remains in a functional state until it is replaced by its successor. At the end of two 
years, we observed a clinical success rate of 100\% in all groups. At the end of one year, Kuo et al. ${ }^{21}$ reported a clinical success rate of $95 \%$ using ProTaper $^{\circledR}$ rotary files. At the end of two years, Morankar et al. ${ }^{20}$ reported a clinical success rate of 92.3\% using HyFlex $\mathrm{CM}^{\circledR}$ rotary files. At the end of 18 months, Ozalp et al. ${ }^{25}$ reported a clinical success rate of $100 \%$ in primary teeth instrumented with manual files. Other researchers have reported clinical success rates ranging from $70-100 \%$ with varying follow-up periods. ${ }^{19,25,35-42}$ This variation in clinical success rates could be due to the influence of the individual body resistance and pathological condition of the tooth before treatment rather than the filling technique per se. ${ }^{24,37,41,42}$

At the end of two years, the radiographic success rates were $97.9 \%, 95.3 \%$, and $89.5 \%$ in the primary teeth instrumented with the Kedo-S pediatric rotary file system, the HERO Shaper rotary file system, and the manual NiTi files, respectively. There was no statistically significant difference in radiographic success between these groups. This result is in consistent with the results obtained by Kuo et al. ${ }^{21}$ Root canals instrumented with manual files have yielded similar results $24,25,35$ to those of the present study. Ozalp et al. ${ }^{25}$ and Pandranki et al. ${ }^{38}$ both reported a success rate of $100 \%$ in primary teeth instrumented with manual file system at the end of a long-term follow-up period. However, in an Indian study, ${ }^{20}$ primary molars instrumented with manual and rotary files yielded very low rates of radiographic success (65.4\% and $66.7 \%$, respectively). The authors considered the radiographically failed teeth to have completely failed, even though they were clinically asymptomatic. Furthermore, the inclusion of pathological root resorption and radiological changes in furcal or periapical areas as radiographical failures could have influenced the success rate of this prior study relative to other studies. ${ }^{35,36}$ The high success rates of the pulpectomized teeth in the present study might have been due to the fact that clinical and radiographic success were determined independently, as not all radiographic failures are associated with clinical symptoms and vice versa. ${ }^{25}$ Another probable reason for differences in the success rates reported in prior research and the present study is variation in the treatment selection criteria for primary molars.

A greater number of radiographic failures were observed in primary teeth instrumented with the HERO Shaper rotary file system than in those instrumented with the Kedo-S pediatric rotary file system. This might have been due to the greater number of overfilled root canals in the primary teeth instrumented with the HERO Shaper rotary file system. This is consistent with the results of Coll and Sadrian, ${ }^{24}$ Chawala et al., ${ }^{35}$ and Pandranki et al., ${ }^{38}$ who observed decreased success rates in overfilled teeth. On the other hand, Bawazir et al. ${ }^{19}$ and Yacobi et al. ${ }^{40}$ observed high success rates in overfilled root canals. Although care was taken not to apply excess pressure with each quarter-turn of the screw during the obturation process, extrusion of the obturating material was observed outside the root canals. Preexisting periradicular pathology and physiological root resorption are probable reasons for overfilling. 19,36,38 The lack of apical constriction and relative difficulty of measuring the working length of primary teeth also contributed to the extrusion of the obturating material. ${ }^{38}$ The overfilling of root canals is unavoidable in some situations, as the dentinal wall of the root canal extending toward the succedaneous tooth are thin and weak and thus may give way during instrumentation. ${ }^{35}$ Furthermore, the zinc oxide cement carried by the Lentulo spiral had a low viscosity and flowed easily, taking the material apically further into the canal as the instrument rotated. ${ }^{41}$ The potential drawbacks of overfilling with zinc oxide-eugenol include foreign body reactions, necrosis of the bone and cementum, deflection of the unerupted permanent tooth, and development of a fibrous capsule that could prevent resorption. ${ }^{24}$ Hence, care should be taken 
with the use of rotary files, especially with the use of a rotary file system designed for permanent teeth in primary teeth. Additionally, the correct root length should be maintained while fitting the rubber stopper onto the Lentulo spiral.

The low success rate of the primary teeth instrumented with manual files might have been due to a high number of underfilled root canals, which form a narrow channel for bacterial growth and can cause reinfection of the root canal. ${ }^{42}$ This explanation would be consistent with the results of Bawazir et al. ${ }^{19}$ and Yacobi et al., ${ }^{40}$ who reported a higher failure rate in underfilled root canals than in overfilled or optimally filled root canals. However, contrary to our results, Coll and Sadrian ${ }^{24}$ reported a higher success rate in underfilled and optimally filled root canals than in overfilled root canals. At the end of the study period, there was no statistically significant difference between the success rates of the different groups of pulpectomized teeth. This might have occurred because the same pulpectomy procedure was used in all three groups, except for the type of root canal instrumentation. A similar result was reported by Pandranki et al. ${ }^{38}$ at the end of two years with the use of manual files.

The use of two-dimensional radiographic imaging is one potential limitation of the present study. The use of three-dimensional imaging, such as cone beam computed tomography (cone beam CT) or micro-CT, would allow researchers to assess every primary tooth. Limited clinical trials have been carried out to compare the success of pulpectomized teeth instrumented with rotary and manual files. Future longitudinal studies should be carried out to compare the use of different rotary file systems. Given that the success of pulpectomized teeth also depends on the type of obturating material, further investigations are in progress to evaluate the synergistic effect of the type of root canal instrumentation and the type of obturating material.
The results of the present study emphasize the use of rotary file systems for root canal instrumentation in primary teeth. Given that there were no differences in the studied parameters between the two studied rotary file systems, operators may choose to use either of these systems, as both are convenient to use with children. However, the added advantages of the Kedo-S pediatric rotary file system-such as a short file length, a short working length, and variable tapers with variable tip diameterssupport its use in primary teeth. ${ }^{13,15-18}$ Additionally, the simple three-file system allows the operator to carry out the procedure more quickly and efficiently in children. However, given that rotary endodontics was only recently introduced to the field of pediatric dentistry, operators must improve their knowledge, skills, and experience with rotary file systems.

\section{CONCLUSIONS}

Based on the results of the present study, it can be concluded that rotary file systems require significantly less time for the instrumentation and obturation of root canals in primary molars compared to manual file systems. Although the HERO Shaper rotary file system took less time for obturation than the Kedo-S pediatric rotary file system, this difference was not statistically significant. The quality of obturation in primary molars instrumented with rotary file systems was found to be superior to that of primary molars instrumented with a manual NiTi file system. However, there was no significant difference in the quality of obturation between primary molars instrumented with a Kedo-S pediatric rotary file system and HERO Shaper rotary file system. At the end of two years, the clinical success rate was $100 \%$ and the radiographical success rates were $97.9 \%, 95.3 \%$, and $89.5 \%$ in primary teeth instrumented with the Kedo-S pediatric rotary file system, the HERO Shaper rotary file system, and the manual NiTi file system, respectively. 
However, there were no significant differences in success rates between these groups.

\section{REFERENCES}

1. Barr ES, Kleier DJ, Barr NV. Use of nickeltitanium rotary files for root canal preparation in primary teeth. Pediatr Dent 1999;21:453-454

2. Barr ES, Kleier DJ, Barr NV. Use of nickeltitanium rotary files for root canal preparation in primary teeth. Pediatr Dent 2000;22:77-78

3. Moghaddam KN, Mehran M, Zadeh HF. Root canal cleaning efficacy of rotary and hand files instrumentation in primary molars. Iran Endod J 2009;4:53-71

4. Hidsmann, M., Gressmann, G., Schafers, F. A comparative study of root canal preparation using FlexMaster and HERO 642rotary NiTi instruments. Int Endod J 2003;36:358-366

5. Sonntag, D., Delschen, S., Stachniss, V. Root canal shaping with manual and rotary NiTi file performed by students. Int Endod J 2003;36:715723

6. Bahrololoomi, Tabrizazadeh M, Salmani L. In vitro comparison of instrumentation time and cleaning capacity between rotary and manual preparation techniques in primary teeth. J Dent 2007;4:59-62

7. Katge F, Patil D, Poojari M, Pimpale J, Shitoot A, Rusawat B. Comparison of instrumentation time and cleaning efficacy of manual instrumentation, rotary systems and reciprocating systems in primary teeth: An in vitro study. J Ind Soc Pedod Prev Dent 2014;32:311-316

8. Finn SB. Morphology of primary teeth. In: Finn SB, editor. Clinical Pedodontics 4th ed. Philadelphia: Saunders Co;1973.p.59-70.

9. Jeevanandan G. Kedo-S Paediatric Rotary Files for Root Canal Preparation in PrimaryTeeth Case Report. J Clin Diagn Res 2017;11:3-5

10. Kaptan F, Sert S, Kayahan B, HaznedarogluF,Tanalap J, Bayirli G. Comparative evaluation of the preparation efficacies of HERO shaper and Nitiflex root canal instruments in curved canals. Oral Surg Oral Med Oral Pathol Oral Radiol Endod 2005;100:636-64.

11. Subramaniam P, Girish Babu KL, Tabrez TA. Effectiveness of Rotary Endodontic Instruments on Smear Layer Removal in Root Canals of
Primary Teeth: A Scanning Electron Microscopy Study. J Clin Pediatr Dent 2016;40:141-146

12. Subramaniam P, Tabrez TA, Girish Babu KL. Microbiological assessment of root canals following use of rotary and manual instruments in primary molars. J Clin Pediatr Dent 2013;38:123127

13. Jeevanandan G, Govindaraju L. Clinical comparison of Kedo-S paediatric rotary files vs manual instrumentation for root canal preparation in primary molars: a double blinded randomised clinical trial. Eur Arch Paediatr Dent 2018;19:273-278

14. Musale PK, Mujawar SAV. Evaluation of the efficacy of rotary vs. hand files in root canal preparation of primary teeth in vitro using CBCT. Eur Arch Paediatr Dent 2014;15:113-120

15. Panchal V, Jeevanandan G, Subramanian E. Comparison of instrumentation time and obturation quality between hand $\mathrm{K}$-file, $\mathrm{H}$-files, and rotary Kedo-S in root canal treatment of primary teeth: A randomized controlled trial. J Indian Soc Pedod Prev Dent 2019;37:75-79

16. Lakshmanan L, Mani G, Jeevanandan G, Ravindran V, Subramanian EMG. Assessing the quality of root canal filling and instrumentation time using Kedo-s files, reciprocating files and kfiles. Braz Dent Sci 2020;23:1-7

17. Divya S, Jeevanandan G, Sujatha S, Subramanian EMG, Ravindran V. Comparison of quality of obturation and post-operative pain using manual vs rotary files in primary teeth - A randomised clinical trial. Indian J Dent Res 2019;30:904-908

18. Juliet S, Jeevanandan G, Govindaraju L, Ravindran V, Subramanian EMG. Comparison Between Three Rotary Files on Quality of Obturation and Instrumentation Time in Primary Teeth - A Double Blinded Randomized Controlled Trial. J Orofac Sci 2020;12:30-34.

19. Bawazir OA, Salama FS. Clinical evaluation of root canal obturation methods in primary teeth. Pediatr Dent 2006;28:39-47.

20. Morankar R, Goyal A, Gauba K, Kapur A, Bhatia SK. Manual versus rotary instrumentation for primary molar pulpectomies- A 24 months randomized clinical trial. Pedia Dent J 2020;28:96-102

21. Kuo C, Wang Y, Chang H, Huang G, Lin C, $\mathrm{Li} \mathrm{U}$, et al. Application of Ni-Ti rotary files for 
pulpectomy in primary molars. J Dent Sci 2006;1:10-15

22. Dandashi MB, Nazif MM, Zullo T, Elliott MA, Schneider LG, Czonstkowsky M. An in vitro comparison of three endodontic techniques for primary incisors. Pediatr Dent. 1993;15:254-256

23. Memarpour M, Shahidi S, Meshki R. Comparison of different obturation techniques for primary molars by digital radiography. Pediatr Dent 2013;35:236-240

24. Coll JA, Sadrian R. Predicting pulpectomy success and its relationship to exfoliation and succedaneous dentition. Pediatr Dent 1996;18:5763

25. Ozalp N, Saroğlu I, Sönmez H. Evaluation of various root canal filling materials in primary molar pulpectomies: an in vivo study. Am J Dent 2005; 18:347-350

26. Romero TO, Gonzalez VM. Comparison between rotary and manual techniques on duration of instrumentation and obturation times in primary teeth. J Clin Pediatr Dent 2011; 35:359-364

27. Makarem Abbas, Ravandeh Navid, Ebrahimi Masoumeh. Radiographic assessment and chair time of rotary instruments in the pulpectomy of primary second molar teeth: a randomized controlled clinical trial. J Dent Res Dent Clin Dent Prospects 2014; 8:84-89

28. Silva LA, Leonardo MR, Nelson-Filho P, Tanomaru JM. Comparison of rotary and manual instrumentation techniques on cleaning capacity and instrumentation time in deciduous molars. J Dent Child (Chic) 2004;71:45-47

29. Crespo S, Cortes O, Garcia C, Perez L. Comparison between rotary and manual instrumentation in primary teeth. J Clin Pediatr Dent 2008;32:295-298

30. Madan N, Rathnam A, Shigli AL, Indushekar KR. K-file vs ProFiles in cleaning capacity and instrumentation time in primary molar root canals: an in vitro study. J Indian Soc Pedod Prev Dent 2011;29:55-61

31. Moghaddam KN, Mehran M, Zadeh HF. Root canal cleaning efficacy of rotary and hand files instrumentation in primary molars. Iran Endod J 2009;4:53-71

32. Babji P, Mehta V, ManjooranT. Clinical Evaluation of rotary system over manual system in deciduous molars: A clinical trial. Int J Pedod Rehabil 2019;4:13-16

33. Govindaraju L, Jeevanadan G, Subramaniam EM. Comparison of quality of obturation and instrumentation time using hand files and two rotary file system in primary molars: A singleblinded randomized controlled trial. Eur J Dent 2017:11:376-379

34. Govindaraju L, Jeevanadan G, Subramaniam EM. Clinical evaluation of quality of obturation and instrumentation time using two modified rotary file systems with manual instrumentation in primary teeth. J Clin Diagn Res 2017;77: 55-58

35. Chawla HS, Setia S, Gupta N, Gauba K, Goyal A. Evaluation of a mixture of zinc oxide, calcium hydroxide, and sodium fluoride as a new root canal filling material for primary teeth. J Indian Soc Pedod Prev Dent 2008;26:53-58

36. Fuks AB, Eidelman E, Pauker N. Rootfillings with endoflas in primary teeth: A retrospective study. J Clin Pediatr Dent 2002;27:41-45

37. Moskovitz M, Sammara E, Holan G. Success rate of root canal treatment in primary molars. J Dent 2005;33:41-47

38. Pandranki J, V Vanga NR, Chandrabhatla SK. Zinc oxide eugenol and Endoflas pulpectomy in primary molars: 24-month clinical and radiographic evaluation. J Indian Soc Pedod Prev Dent 2018;36:173-180

39. Ramar K, Mungara J. Clinical and radiographic evaluation of pulpectomies using three root canal filling materials: An in-vivo study. J Indian Soc Pedod Prev Dent 2010;28:25-29

40. Yacobi R, Kenny DJ, Judd PL, Johnston DH. Evolving primary pulp therapy techniques. J Am Dent Assoc 1991;122:83-85

41. Machida Y. Root canal obturation in primary teeth: a review. Jap Dent Assoc J 1983; 36:796802.

42. Mortazavi M, Mesbahi M. Comparison of zinc oxide and eugenol, and Vitapex for root canal treatment of necrotic primary teeth. Int J Paediatr Dent 2004;14:417-424 


\section{How to cite this article:}

KL Girish Babu and Guraj Hebbar Kavyashree. Evaluation of the clinical efficiency of rotary and manual files for root canal instrumentation in primary teeth pulpectomies: A comparative randomized clinical trial. Contemp Pediatr Dent 2021:2(1):21-34

\section{Declarations}

Acknowledgements: Not applicable.

Conflict of Interest Statement: The authors disclose no potential conflicts of interest.

Ethics Statement: Ethical clearance to conduct this study was obtained from the Institutional Ethics Committee (IEC/HIMS/RR76).

Informed Consent: Informed consent and assent were obtained from all participants.

Author contributions: Conception and design: All Authors; Acquisition of data: All Authors; Interpretation of data: All Authors; Drafting article: All Authors; Revision artice: All Authors; Final approval: All Authors

Funding: This work is not finantiated.

Data Availability: The data used to support the findings of this study can be made available upon request to the corresponding author.

Peer-review: Externally double-blinded peer-reviewed. 